\title{
TU/e emonownen

\section{Gas flow characteristics of a time modulated APPJ : the effect of gas heating on flow dynamics}

\section{Citation for published version (APA):}

Zhang, S., Sobota, A., Veldhuizen, van, E. M., \& Bruggeman, P. J. (2015). Gas flow characteristics of a time modulated APPJ : the effect of gas heating on flow dynamics. Journal of Physics D: Applied Physics, 48, 015203-1/14. https://doi.org/10.1088/0022-3727/48/1/015203

\section{Document license:}

TAVERNE

DOI:

10.1088/0022-3727/48/1/015203

Document status and date:

Published: 01/01/2015

\section{Document Version:}

Publisher's PDF, also known as Version of Record (includes final page, issue and volume numbers)

\section{Please check the document version of this publication:}

- A submitted manuscript is the version of the article upon submission and before peer-review. There can be important differences between the submitted version and the official published version of record. People interested in the research are advised to contact the author for the final version of the publication, or visit the $\mathrm{DOI}$ to the publisher's website.

- The final author version and the galley proof are versions of the publication after peer review.

- The final published version features the final layout of the paper including the volume, issue and page numbers.

Link to publication

\section{General rights}

Copyright and moral rights for the publications made accessible in the public portal are retained by the authors and/or other copyright owners and it is a condition of accessing publications that users recognise and abide by the legal requirements associated with these rights.

- Users may download and print one copy of any publication from the public portal for the purpose of private study or research.

- You may not further distribute the material or use it for any profit-making activity or commercial gain

- You may freely distribute the URL identifying the publication in the public portal.

If the publication is distributed under the terms of Article 25fa of the Dutch Copyright Act, indicated by the "Taverne" license above, please follow below link for the End User Agreement:

www.tue.nl/taverne

Take down policy

If you believe that this document breaches copyright please contact us at:

openaccess@tue.nl

providing details and we will investigate your claim. 
Gas flow characteristics of a time modulated APPJ: the effect of gas heating on flow dynamics

This content has been downloaded from IOPscience. Please scroll down to see the full text.

2015 J. Phys. D: Appl. Phys. 48015203

(http://iopscience.iop.org/0022-3727/48/1/015203)

View the table of contents for this issue, or go to the journal homepage for more

Download details:

IP Address: 131.155.124.215

This content was downloaded on 07/01/2015 at 09:36

Please note that terms and conditions apply. 


\title{
Gas flow characteristics of a time modulated APPJ: the effect of gas heating on flow dynamics
}

\author{
S Zhang ${ }^{1}$, A Sobota ${ }^{1}$, E M van Veldhuizen ${ }^{1}$ and $\mathrm{P}$ J Bruggeman ${ }^{1,2}$ \\ ${ }^{1}$ Department of Applied Physics, Eindhoven University of Technology, PO Box 513, 5600 MB, \\ Eindhoven, The Netherlands \\ 2 Department of Mechanical Engineering, University of Minnesota, 111 Church Street SE, Minneapolis, \\ MN 55455, USA \\ E-mail: s.zhang@tue.nl
}

Received 8 July 2014, revised 8 October 2014

Accepted for publication 11 November 2014

Published 8 December 2014

\begin{abstract}
This work investigates the flow dynamics of a radio-frequency (RF) non-equilibrium argon atmospheric pressure plasma jet. The RF power is at a frequency of $50 \mathrm{~Hz}$ or $20 \mathrm{kHz}$. Combined flow pattern visualizations (obtained by shadowgraphy) and gas temperature distributions (obtained by Rayleigh scattering) are used to study the formation of transient vortex structures in initial flow field shortly after the plasma is switched on and off in the case of $50 \mathrm{~Hz}$ modulation. The transient vortex structures correlate well with observed temperature differences. Experimental results of the fast modulated $(20 \mathrm{kHz})$ plasma jet that does not induce changes of the gas temperature are also presented. The latter result suggests that momentum transfer by ions does not have dominant effect on the flow pattern close to the tube. It is argued that the increased gas temperature and corresponding gas velocity increase at the tube exit due to the plasma heating increases the admixing of surrounding air and reduces the effective potential core length. With increasing plasma power a reduction of the effective potential core length is observed with a minimum length for $5.6 \mathrm{~W}$ after which the length extends again. Possible mechanisms related to viscosity effects and ionic momentum transfer are discussed.
\end{abstract}

Keywords: flow pattern, shadowgraphy, gas temperature, vortex structures, Kelvin Helmholtz instability, effective potential core flow

(Some figures may appear in colour only in the online journal)

\section{Introduction}

Cold atmospheric pressure plasma jets (APPJs) are promising tools for material processing and biomedical applications such as wound healing, disinfection and decontamination [1-3]. They operate in open air with argon or helium as feed gas where the effluent of the jet extends into open air environment, which leads to air entrainment. Knowing the characteristics of the flow is crucial for understanding the distribution, evolution, transport, and chemical reactions of reactive species produced in and carried by the flow, on which the applications rely.

The gas jet has been extensively investigated in the context of fluid dynamics, thermal plasmas and combustion. In many of these studies Reynolds numbers in the range 1000-3000 are of interest. These conditions correspond to a transition or semi-turbulent jet [4]. In fluid dynamics, the flow structure of a gas jet is divided into (potential) core region, transition region, self-similar region and terminal region based on the local flow velocity distributions [5]. The potential core corresponds to the region in which the velocity field is not significantly altered from the nozzle. In the transition region the surrounding air starts to admix with the jet and (regular) vortex structures are formed. In the self-similar region and terminal region the jets is no longer strongly dependent on the initial flow conditions of the nozzle and the vortex structures break down to smaller scales and can depending on the 
Table 1. Research domains addressing the flow dynamics of a gas jet.

\begin{tabular}{|c|c|c|c|}
\hline & & Parameters & Reference \\
\hline Fluid dynamics & & 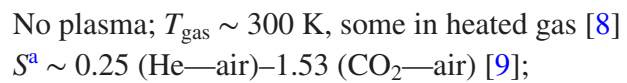 & {$[5-8,10-15]$} \\
\hline Combustion & & $T_{\text {flame }} \sim 1000-3000 \mathrm{~K} ; S \sim 0.1-1$ & {$[16,17]$} \\
\hline Thermal plasmas & He jets & $\begin{array}{l}T_{e} \sim T_{i} \sim T_{g} \sim 10000 \mathrm{~K} \\
\text { Ionization degree }>1 \% ; S \sim 0.07[18] \\
T_{g} \sim 300-500 \mathrm{~K} ; n_{e} \sim 10^{11}-10^{13} \mathrm{~cm}^{-3} \\
\text { Ionization degree: } 10^{-6}-10^{-8} ; S \sim 0.15\end{array}$ & {$[18-21]$} \\
\hline APPJs & Ar jets (this work) & $\begin{array}{l}T_{g} \sim 300-900 \mathrm{~K} ; n_{e} \sim 10^{12}-10^{14} \mathrm{~cm}^{-3}[22] \\
\text { Ionization degree: } 10^{-5}-10^{-7} ; S \sim 0.5-1.54\end{array}$ & {$[23-30]$} \\
\hline
\end{tabular}

${ }^{\text {a }} S$ indicates the density ratio of the core zone to the ambient surroundings.

Reynolds number lead to turbulence [5-7]. Table 1 gives the main parameters of the effluent for a typical example taken from fluid dynamics, combustion, thermal plasmas and nonequilibrium plasmas.

Labus et al reported that the potential core length of an axisymmetric free helium jet depends on the Reynolds number at the nozzle exit. It reaches a maximum at a Reynolds number of roughly 1500 and decreases afterwards [5]. Buoyancy has been found to play a key role in the flow transition from laminar to turbulent flow in the case of helium jets [13, 14]. This effect has been observed for Richardson numbers between $3.53 \times 10^{-3}$ and $19 \times 10^{-3}$ [13]. The jet development for a low density heated air gas jet at a Reynolds number of 10000 with laminar flow at the exit of the nozzle is dominated by large scale vortex structures. These shear layer structures also became more organized as the jet density was reduced relative to the density of the ambient gas [8]. Both the flow dynamics and possible instabilities in the jet strongly depend on the conditions at the nozzle exit including the Reynolds number, nozzle geometry and initial velocity $[6,11]$. Hence it is often difficult to make general conclusions on flow structures of different jets.

Flow dynamics in combustion is of the utmost importance as it determines the mixing of fuel and air in non-premixed flames and influences flame length [16, 17]. Buoyancy is often important due to significant gas heating in this case (1000-3000 K).

Pfender et al reported on the entrainment of surrounding cold gas into an argon thermal plasma jet with shadowgraphy and the coherent anti-Stokes Raman scattering technique and confirmed that large scale flow structures govern the air entrainment processes in the plasma jet close to the nozzle exit and that the onset of turbulence results from the breakdown of these flow structures [20]. Work of the same group [18] showed that the organized vortex structures in a low density argon jet with the Reynolds number 1000 and the ratio of jet to ambient density of 0.07 are responsible for the rapid entrainment of external air. Similar coherent structures have been found for a thermal plasma. However at higher flow rates, small scale turbulences are formed which is enhanced by the fluctuations from the arc observed under these conditions. These findings have been reproduced in models by Trelles [19].

Flow dynamics in non-equilibrium atmospheric pressure jets have been received recently a lot of attention. Bradley et al performed Schlieren photography on a micro-plasma jet excited by $10 \mathrm{kHz} \mathrm{AC}$ with a voltage amplitude between $6 \mathrm{kV}$ and $9 \mathrm{kV}$ fed by helium at atmospheric pressure [24-26]. They reported that the length of the laminar flow regime when the plasma is on is shorter than when the plasma is off. Although gas temperatures have not been reported, gas heating was identified as the key mechanism leading to the velocity increase of the gas and the reduction of the laminar length. Foletto et al [27] reported the distance from the dielectric tube exit to the transition point under different Reynolds numbers (100$500)$, applied voltage $(3.0-5.5 \mathrm{kV})$, and operating frequency $(2-50 \mathrm{kHz})$ in a similar AC driven helium jet. The transition point being the spatial location at which the transition from laminar to turbulent flow is observed. Foletto et al proposed that the ionic wind produced by the plasma influences the position of the transition point. The effect of gas temperature was not considered in this work. Robert et al studied the influence of geometrical features, the pulse repetition rate, and the presence of a metallic target on the rare gas flow structuration in a helium plasma jet [28]. They confirmed that the plasma affected the transition from the laminar to turbulent flow regime for the helium and neon plasma jet [29]. The authors also speculated that for argon plasma jets the plasma action also might play a key role in the transition from a laminar to a turbulent flow. Boselli et al researched the fluid-dynamic behavior of a nanosecond pulsed helium APPJ with a maximum excitation frequency of $1 \mathrm{kHz}$ by means of Schlieren photography [30]. They found that a transient turbulent structure is formed and propagates along the gas flow after the plasma is ignited. They proposed different possible mechanisms such as gas heating, local pressure increase, the change of transport properties of the fluid and the momentum transfer between ions and neutrals to explain the observed turbulent front. Recently Papadopoulos et al reported that the flow pattern change of a helium plasma jet $(10 \mathrm{kHz}, 0-30 \mathrm{kV}$ peak to peak) is related to the electrohydrodynamic force and the gas heating has little effect [31]. These conclusions have been obtained mainly by simulations and the measurements of the gas temperature in jet by the rotational temperature of $\mathrm{N}_{2}(C)$. However, it is possible that the obtained gas temperature is an underestimate as it has been shown that the emission profile is hollow [32] and most likely the temperature of the outer plasma core has been measured. In addition the authors have assumed that the electrohydrodynamic force has a spatially uniform distribution. 


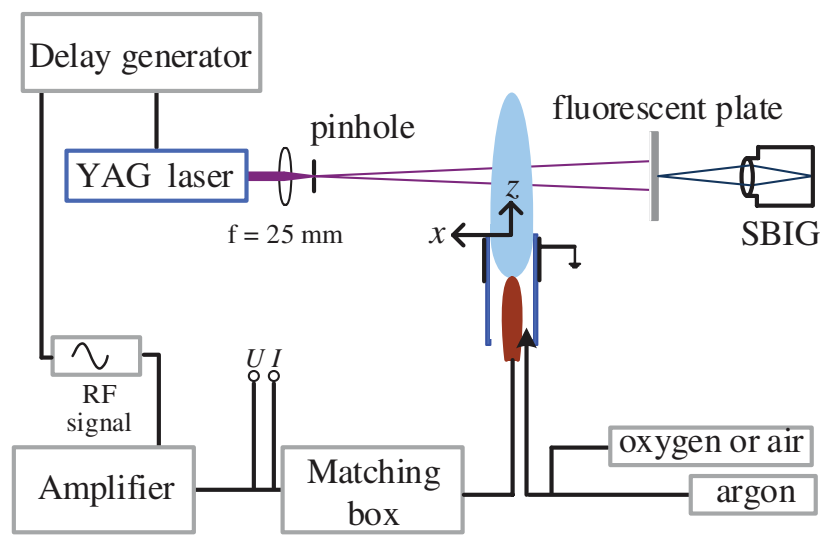

Figure 1. Schematic representation of the shadowgraphy set up for measuring flow dynamics.

The existing literature on the flow characteristics of cold atmospheric pressure plasma jets has several common points. There is a transition point for a gas jet without plasma from large-scale uniform (laminar in the references) to non-uniform (turbulent in the references) flow. The determining factor for that transition of the flow pattern in the effluent is still under debate as illustrated by the different proposed mechanism for similar jets. The physics behind the transient vortex structure in the flow pattern shortly after the plasma is switched on or off as reported by Boselli et al is at least only poorly understood. In addition, the reported results had a strong emphasis on He jets in air, which has a density ratio of jet and ambient gas of 0.14 while the Ar/air jet has a density ratio of 1.38 . This might lead to significant differences in flow and a likely reduction of buoyancy driven effects.

Simulation work might be a suitable method to obtain the mechanism behind these phenomena. However, the simulations dealing with plasma-flow interactions [19, 33-35] are mainly developed for thermal plasmas and have not reached the same level of detail for non-equilibrium plasma [36]. The reported work in atmospheric pressure non-equilibrium plasma jets has mainly been based on Schlieren imaging while influencing factors such as gas temperatures and ion fluxes have not been measured consistently.

The existing literature on APPJs tends to divide the effluent in zones of laminar and turbulent flow based on Schieren imaging. In the field of fluid mechanics, this is supported by flow velocity field measurement (standard deviation of the velocity) [37] or the power spectra measurement $[8,38]$. In some cases, the plasma does not extend in the far effluent region and ends in the transition region in which only large scale vortex structures are observed. This is also the case in the work presented in this article. To this end, we will refer to effective potential core length. Effective is used in this terminology as no velocity profiles are obtained as should be the case for an exact determination of the potential core region.

In fluid dynamics, carefully designed nozzles are used while this is not the case with plasma jets. In several cases a high voltage needle is present in the quartz tube that may influence the initial flow conditions at the nozzle and trigger

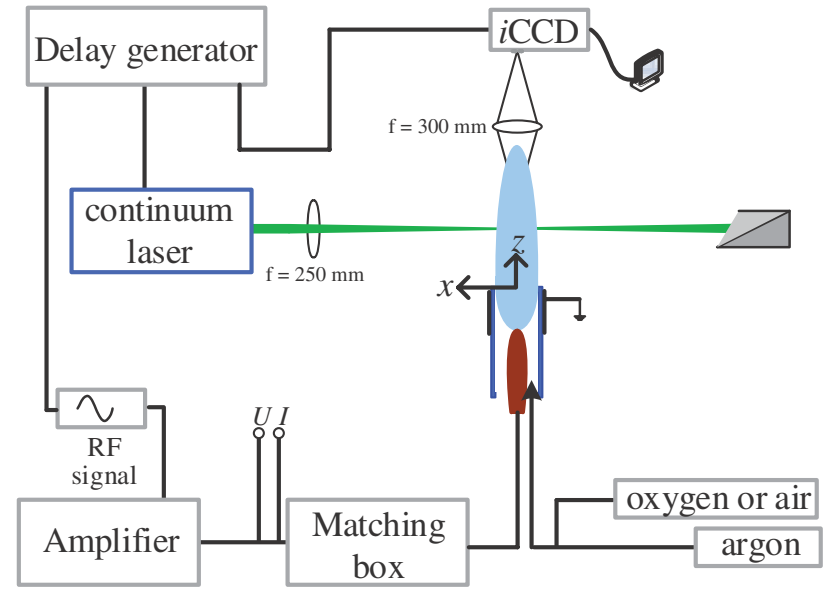

Figure 2. Schematic representation of the setup for measuring gas temperature by Rayleigh scattering.

additional disturbances to the flow. A direct comparison with jet studies using nozzles should thus be done with care.

In this work, shadowgraphy is used to visualize the time resolved flow dynamics of the effluent of an argon radiofrequency (RF) atmospheric pressure plasma jet. The plasma jet is modulated differently by a fast mode and a slow mode in order to investigate the temporal development of the flow pattern on different time scales when the plasma is on and/or off. Complementary measurements were made of temporally and spatially recorded gas temperatures and plasma optical emissions profiles, which allows us to verify the thermal effect on flow dynamics.

The article starts with a description of the experimental setup including the plasma jet, the shadowgraphy setup and the Rayleigh scattering setup. The experimental results follow, consisting of the shadowgraphy images, the gas temperature, and the visible plasma emission results under different operating conditions. Next the driving forces behind the the change in the flow pattern are discussed followed by the conclusions.

\section{Experimental setup}

The plasma jet used in this work has been previously described $[39,40]$. The jet is excited by time modulated 13.6 MHz RF voltages. Argon mixed with $2 \%$ oxygen is used as feed gas.

The modulation signal is produced by a delay generator (BNC, Model 575 pulse/delay generator). In this work, the RF signal is modulated at two frequencies: a fast modulation mode at $20 \mathrm{kHz}$ with duty cycle of $20 \%$ (10 $\mu$ s on, $40 \mu \mathrm{s}$ off) and a slow modulation mode at $50 \mathrm{~Hz}$ with duty cycle of $50 \%$ (10 ms on, $10 \mathrm{~ms}$ off). The delay generator is also used to synchronize the plasma jet and the laser.

The average power dissipated by the plasma has been measured as in [41]. In the case of the $20 \mathrm{kHz}$ modulation mode, the average power is $3.5 \mathrm{~W}$, while for the $50 \mathrm{~Hz}$ modulation mode, the average power is $6.5 \mathrm{~W}$ if not otherwise indicated. This difference in average powers comes from the fact that at $20 \mathrm{kHz}$ the plasma was on for only $20 \%$ of each modulation period (17.5 W of dissipated power while plasma is on), and 

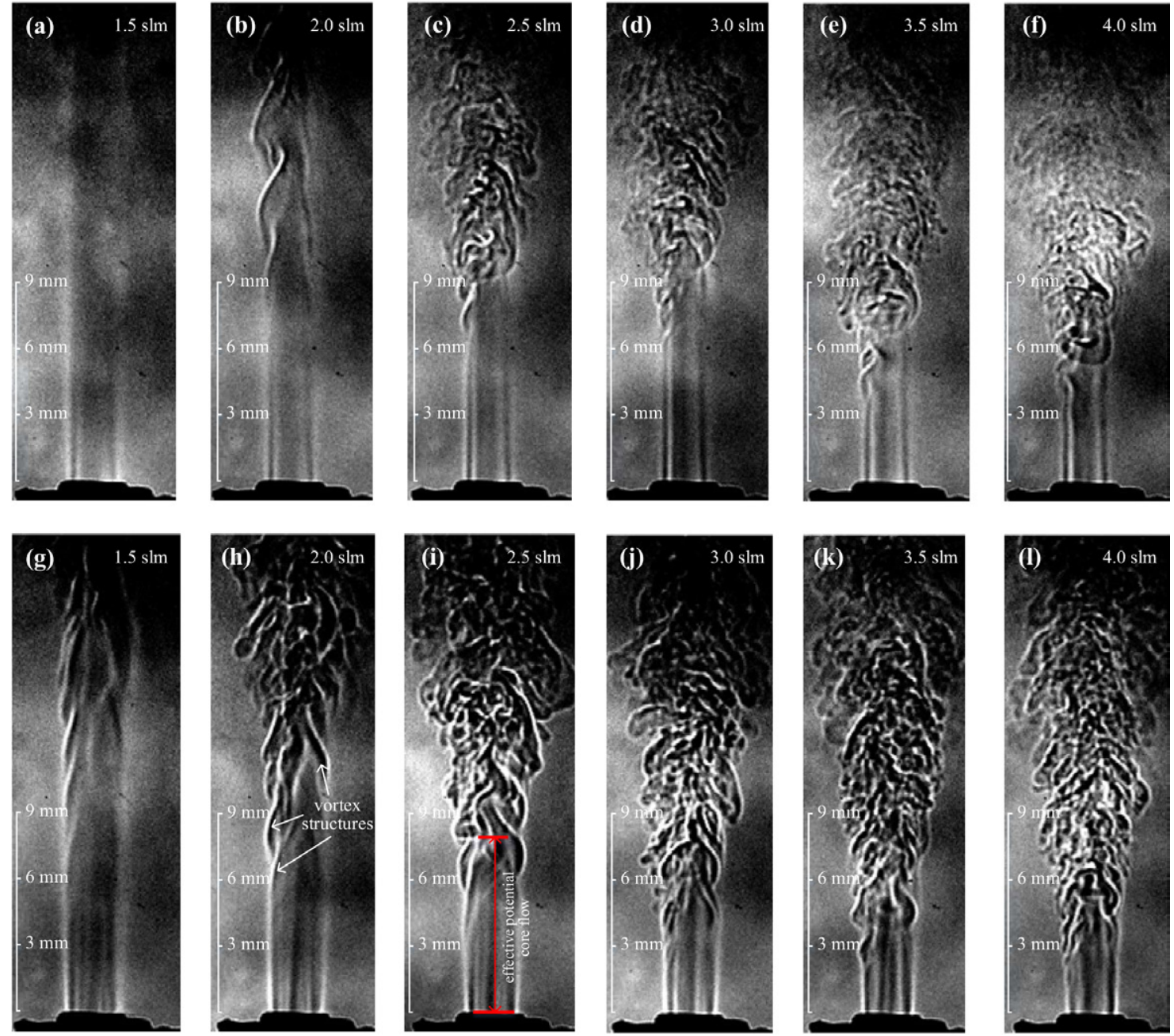

Figure 3. Flow pattern at different gas flows. Images $(a)-(f)$ are obtained during the plasma-off phase at $19 \mathrm{~ms}$, and images $(g)-(l)$ are obtained during the plasma-on phase at $9 \mathrm{~ms}$. The feed gas is argon mixed with $2 \%$ oxygen. The mass flow rate is marked on the images. The power is $8.3 \mathrm{~W}$ with $50 \mathrm{~Hz}$ modulation, $50 \%$ duty cycle.

$50 \%$ of the time at $50 \mathrm{~Hz}(13 \mathrm{~W}$ of dissipated power while plasma is on).

The setup used in shadowgraphy experiments is shown in figure 1. A Big Sky ULTRA CFR Nd:YAG laser is used to produce a laser beam which is focused by a spherical convex lens $(f=25 \mathrm{~mm})$ onto a $50 \mu \mathrm{m}$ pinhole. The plasma jet is located in a way that the divergent laser beam can cover the plasma effluent. A fluorescent plate $(50 \times 50 \mathrm{~mm})$ is placed between the plasma jet and a CCD camera (SBIG $2000 \mathrm{XM}$, array dimensions $11.8 \times 8.9 \mathrm{~mm}, 1600 \times 1200$ pixels) with the fluorescent plane on the side of the jet. The position of the jet is adjusted to obtain a full picture by the camera. The laser operates at a wavelength of $266 \mathrm{~nm}$ and has a pulse duration of $8 \mathrm{~ns}$. The shadowgraphy images are recorded in a single shot.

The gas temperature is obtained by Rayleigh scattering. The principle of Rayleigh scattering and the setup has been described in detail in [39, 42]. It is noted that the Rayleigh scattering cross sections of air, $\mathrm{O}_{2}$, and Ar differ less than $2 \%[43,44]$. Hence, the Rayleigh signal intensity does not significantly depend on the varying gas composition in the effluent. In order to compare the gas temperature distribution with the flow dynamics by shadowgraphy, a laser sheath is scanned through the plasma plume as is shown in figure 2 . The output laser beam from a Nd:YAG laser (Continuum Powerlite Precision II 8010) has a diameter of $5 \mathrm{~mm}$. A cylindrical convex lens $(f=25 \mathrm{~mm})$ is utilized to focus the cylindrical laser beam into the laser sheath. The scattered signal is collected by an intensified CCD camera (Stanford Computer Optics, 4 Picos, 200 ps). The same delay generator is used to synchronize all the signals. Other details of the setup are identical to [39].

The photographs of the effluent were obtained with the intensified CCD camera. Color images of the plasma jet are taken with a CCD photo camera (SONY, Model: DSC-R1).

\section{Experimental results}

A description of the APPJ effluent is introduced to clarify the terminology. As is shown later, when the plasma induced flow emanates into the surrounding air, the flow characteristics remain determined by the flow at the quartz tube exit for a certain distance, showing no large-scale vortex structures. Then subsequent vortex structures on the edge finally reach 

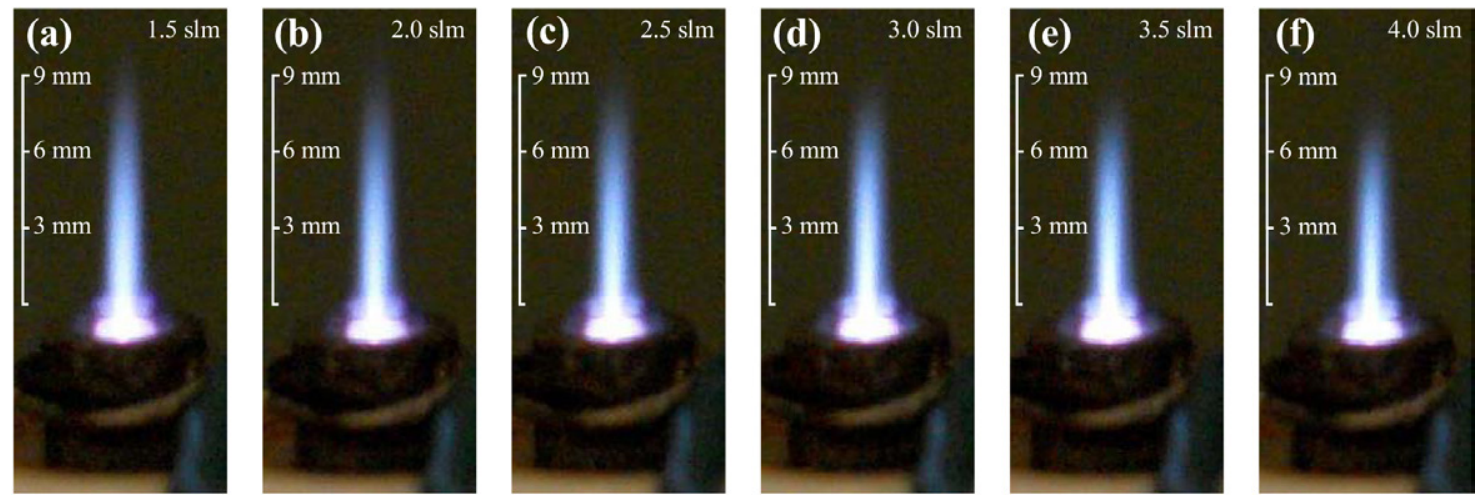

Figure 4. Time averaged images of the visible plasma effluent. The feed gas is argon mixed with $2 \%$ oxygen. The argon flow rate from (a) $-(f)$ is $1.5 \mathrm{slm}, 2.0 \mathrm{slm}, 2.5 \mathrm{slm}, 3.0 \mathrm{slm}, 3.5 \mathrm{slm}, 4.0 \mathrm{slm}$ respectively. The average dissipated power is $8.3 \mathrm{~W}$ and the experimental conditions are the same as in figure 3 .
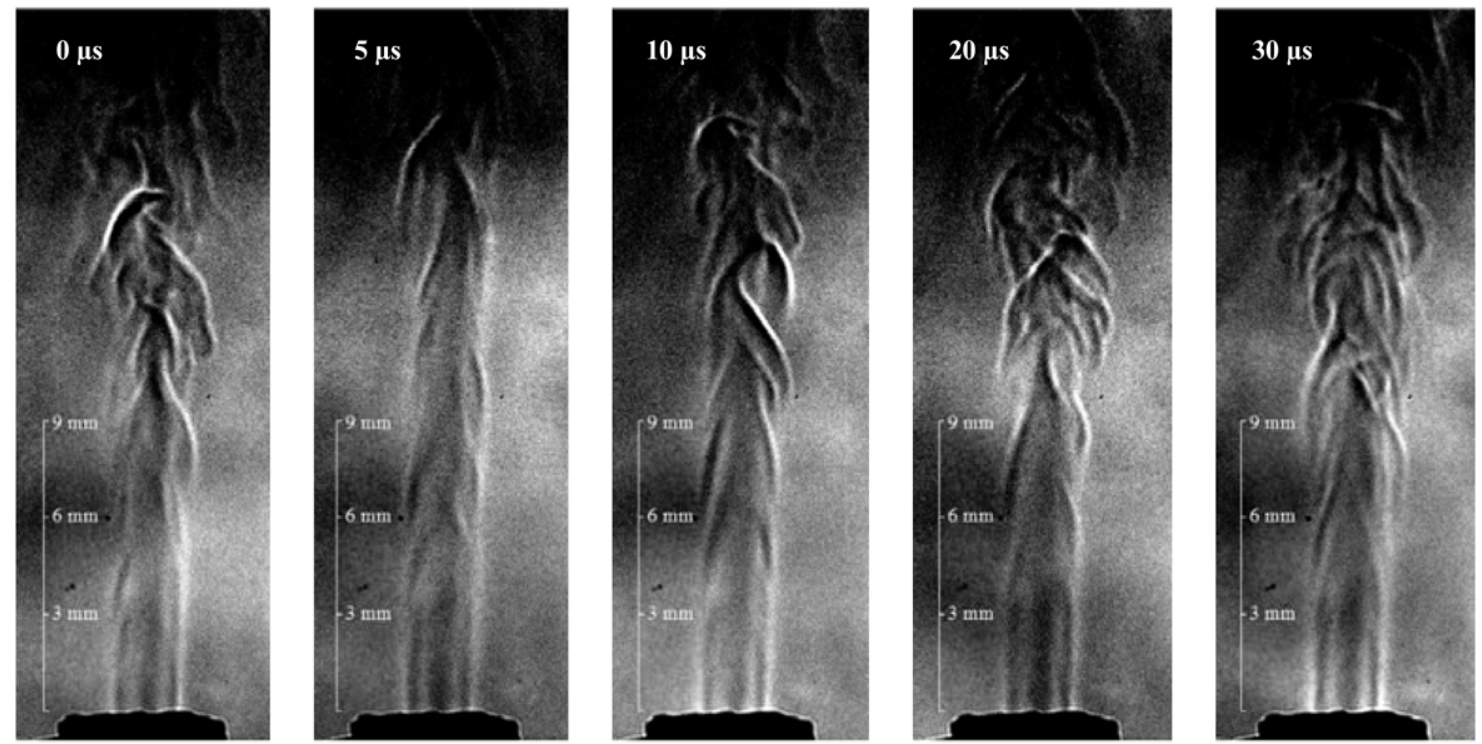

Figure 5. The time resolved shadowgraphy images for the fast modulation case ( $20 \mathrm{kHz}$ ). The plasma is on from $0 \mu \mathrm{s}$ to $10 \mu \mathrm{s}$ and off from $10 \mu \mathrm{s}$ to $50 \mu \mathrm{s}$. The feed gas is argon with $2 \%$ air. The flow rate is $1 \mathrm{slm}$.

the center line of the effluent. This region is marked as 'effective potential core flow' (in figures $3(h)$ and $(i)$ ) following the classification in [20]. As velocity measurements were not performed in this work, the term 'potential core flow' cannot conclusively be linked to this region of the APPJ; based on the similarities of the flow profile and velocity measurements pending, the term 'effective potential core flow' is used instead. The position where vortex structures reach the center line marks the beginning of the 'transition region'. As is seen from shadowgraphy images, the initial large scale vortex structures breaks into small scale structures as the flow goes downstream, which is similar as described in $[7,20]$. Note that the plasma is mainly present in the potential core zone and penetrates only moderately the transition region (see further). To this end this work focuses on the potential core and transition region.

\subsection{Flow patterns at different gas flow rates}

The results shown in this section are for the $50 \mathrm{~Hz}$ modulation of the RF jet. The plasma is switched on at $0 \mathrm{~ms}$ and off at $10 \mathrm{~ms}$ until $20 \mathrm{~ms}$. The flow patterns obtained during the plasma-off phase in one modulation period are shown in figures $3(a)-(f)$, while the flow patterns obtained when the plasma is on are shown in figures $3(g)-(l)$. The effective potential core flow length is shorter for a larger gas flow rate and during the plasma-on phase when compared to the plasma-off phase. The same observation was also reported in [24-27].

Images of the visible plasma emission in the effluent, taken for the same conditions as in figure 3 , are shown in figure 4 . The length of the plasma effluent decreases slightly from $8 \mathrm{~mm}$ to $6 \mathrm{~mm}$ when the flow increases from $1.5 \mathrm{slm}$ to $4 \mathrm{slm}$, while the vortex structure at the edge of the effluent appear at $\sim 9 \mathrm{~mm}$ to $\sim 3 \mathrm{~mm}$.

\subsection{Flow patterns for the $20 \mathrm{kHz}$ modulated jet}

As is shown in figure 5 , at $20 \mathrm{kHz}$ modulation frequency the flow pattern is not significantly changed between the plasma-on and off case during one modulation period. Vortex 

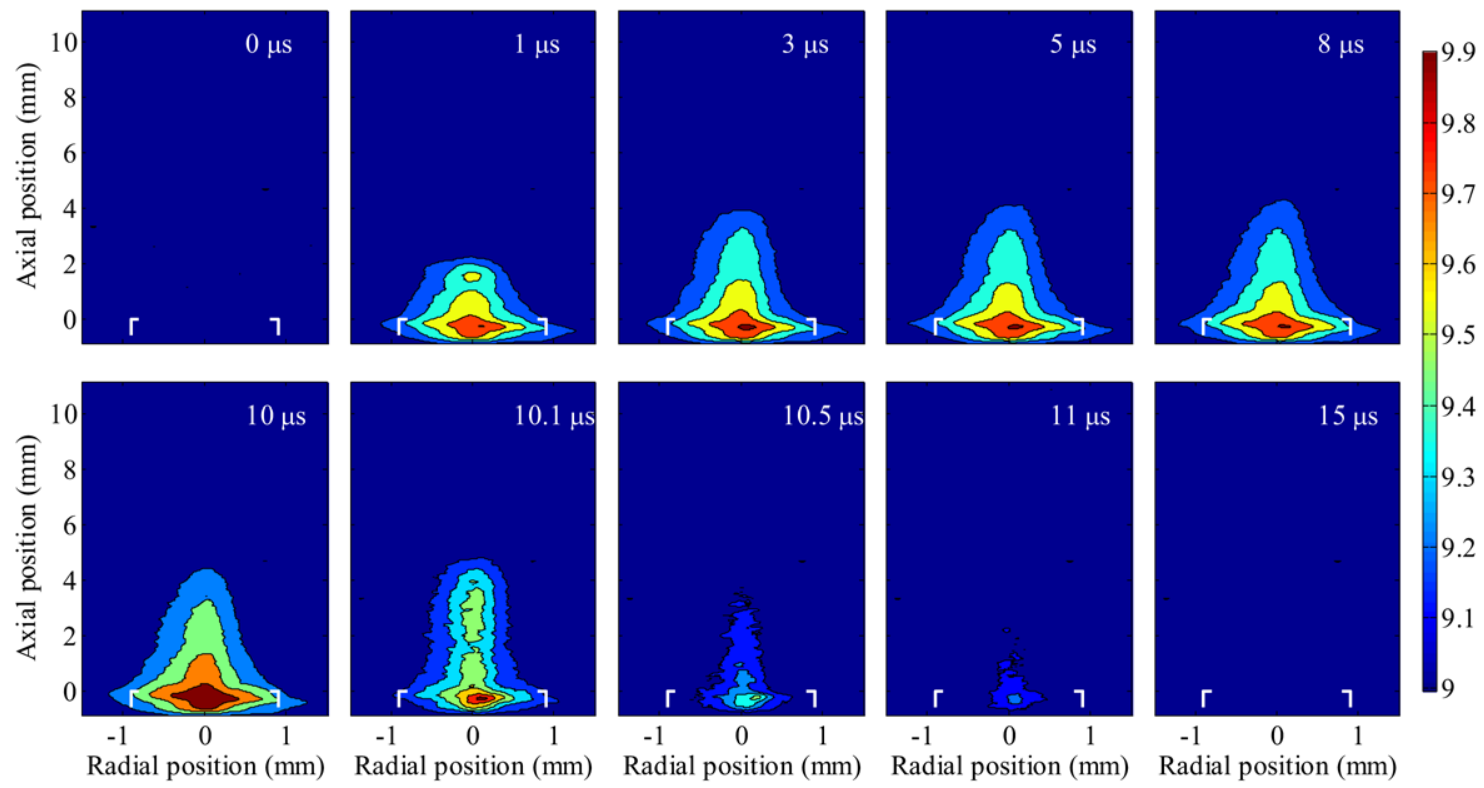

Radial position (mm) Radial position $(\mathrm{mm}) \quad$ Radial position $(\mathrm{mm})$

Figure 6. The time resolved plasma emission. The operating conditions are the same as in figure 5. The white corners indicate the end of the quartz tube. The intensity is shown in a logarithmic scale in arbitrary units.
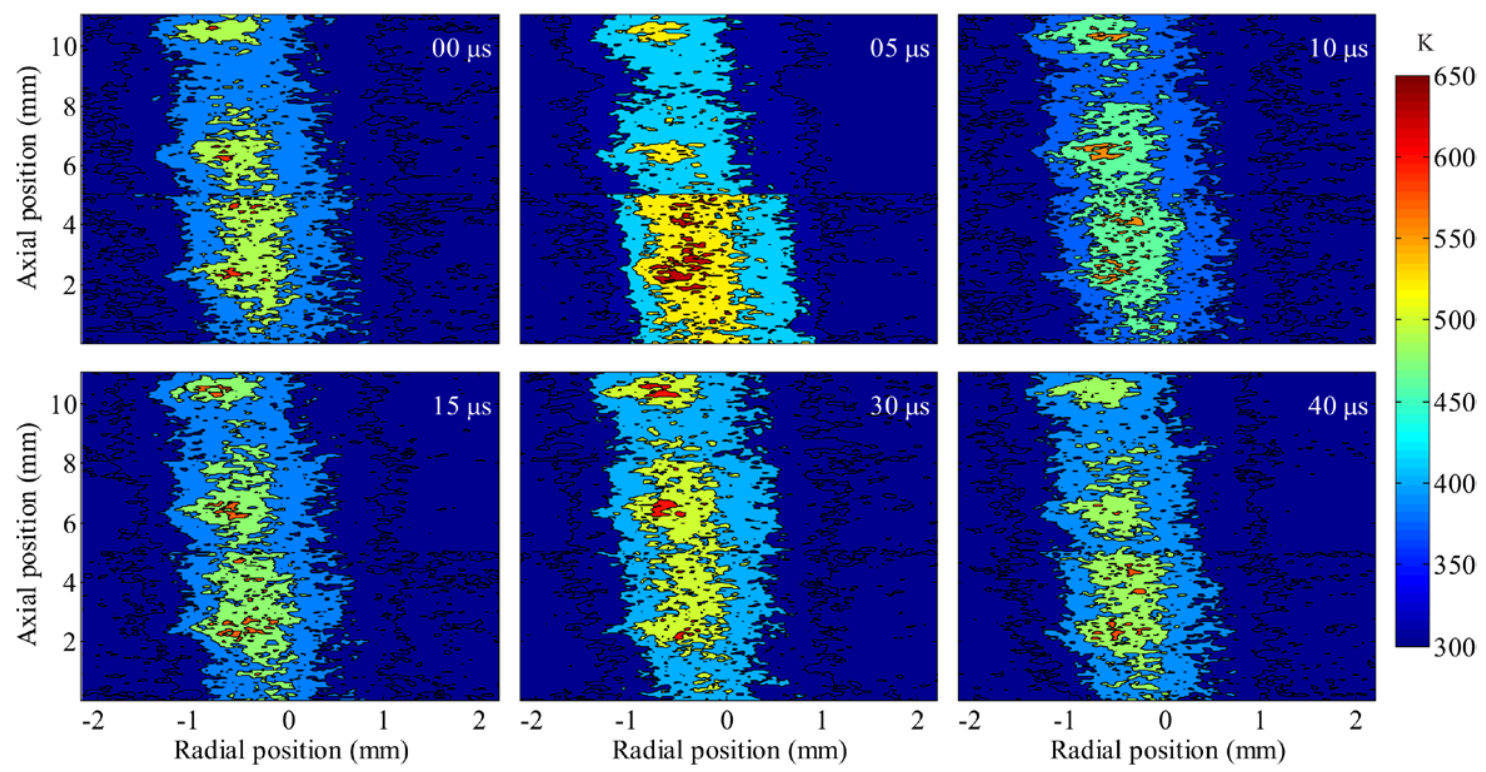

Figure 7. The time resolved gas temperature under $20 \mathrm{kHz}$ modulation. The operating conditions is the same as in figure 5.

structures appear at $\sim 4 \mathrm{~mm}$ and the profile of the effluent remains constant during the modulation period.

Time resolved plasma emission and gas temperature profiles are shown in figures 6 and 7. As is shown in figure 6, the intensity of the plasma emission increases quickly after the plasma is switched on and the strongest plasma emission lies inside the quartz tube close to the exit. After the plasma is switched off, the intensity decreases within $0.5 \mu \mathrm{s}$.

In figure 7, the maximum gas temperature is on the axis and it decreases to almost room temperature at the $\sim 1 \mathrm{~mm}$ radial position. This temperature distribution does not change significantly during the whole period, which is consistent with the same flow dynamics between the plasma-on and off phase.
It should be noted that for the gas temperature measurement, since the diameter of the laser beam is only $5 \mathrm{~mm}$, it can not cover the entire effluent zone. As a result, the gas temperature distribution of the entire effluent is obtained by combining three different zones.

\subsection{Time resolved flow patterns for the $50 \mathrm{~Hz}$ modulated jet}

The time resolved flow pattern after the plasma is switched on $(0 \mathrm{~ms})$ is shown in figure 8 . The main characteristic of the time resolved shadowgraphy is the formation of a transient vortex across the whole diameter of the effluent at $0.1 \mathrm{~ms}$. Subsequently the structure expands along the gas flow and 

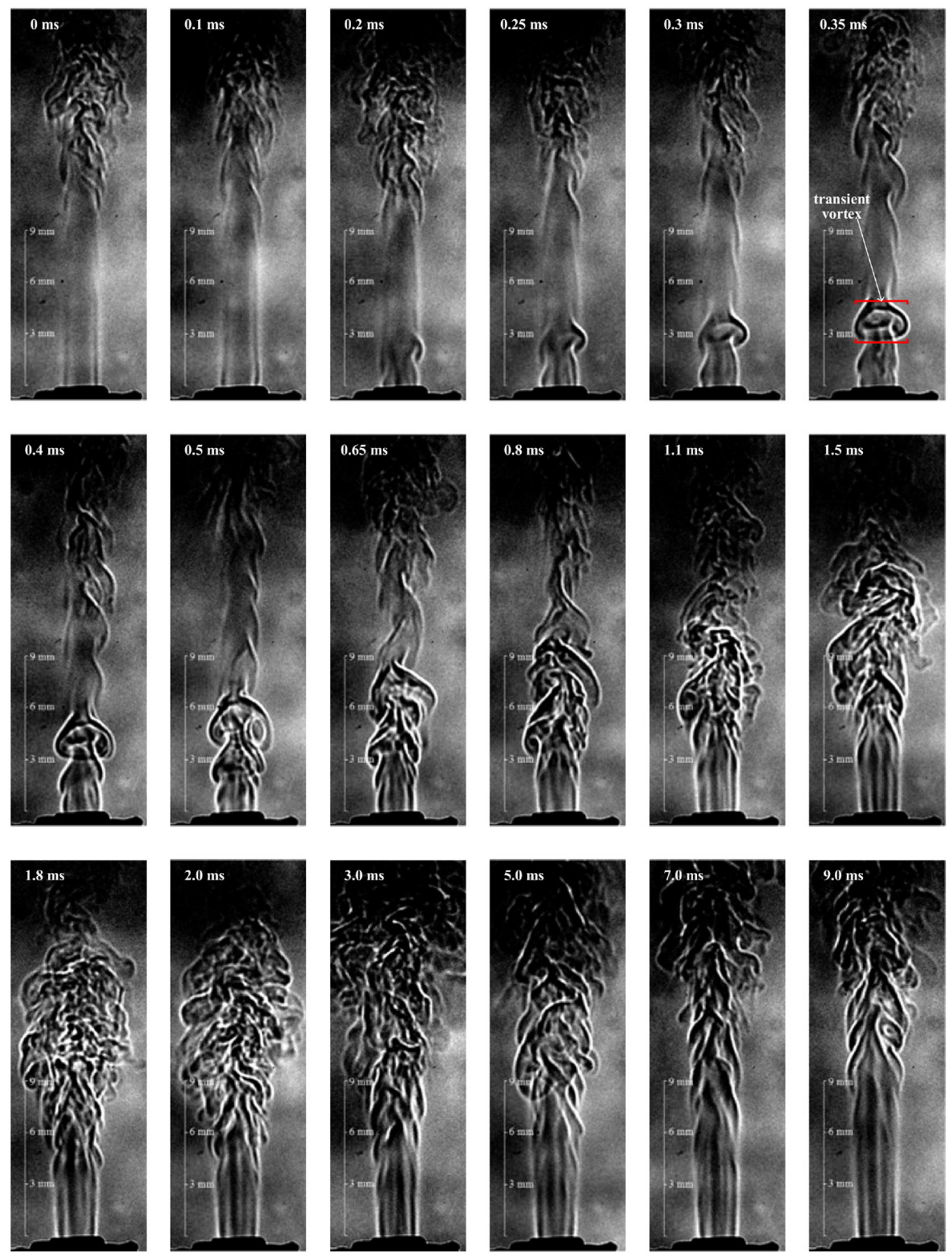

Figure 8. The time resolved shadowgraphy under $50 \mathrm{~Hz}$ modulation. The feed gas is argon mixed with $2 \%$ oxygen. The flow rate is constant at $2 \mathrm{~s} / \mathrm{m}$. The plasma is switched on at $0 \mathrm{~ms}$ and off at $10 \mathrm{~ms}$. The transient vortex structure is marked on the image recorded at $0.35 \mathrm{~ms}$.

its size increases radially and axially until it evolves into the newly formed expanding turbulent zone. After the plasma is switched off (at $10 \mathrm{~ms}$ ) as shown in figure 9, at $10.1 \mathrm{~ms}$ a contraction of the plasma effluent flow in radial direction occurs and subsequently a similar irregular flow structure is formed as during the ignition process. This structure propagates and expands along the gas flow direction during $\sim 2 \mathrm{~ms}$.
Figure 10 shows that the visible plasma length increases untill $0.4 \mathrm{~ms}$, when it reaches its steady state. When the plasma is switched off, the plasma emission vanishes within $1 \mathrm{~ms}$. Note that the plasma emission reaches its maximum size within $\sim 3 \mu$ s for $20 \mathrm{kHz}$ case as can be seen in figure 6 . A higher preionization degree, metastable molecule and atom density, or the higher dissipated power and voltage for $20 \mathrm{kHz}$ 

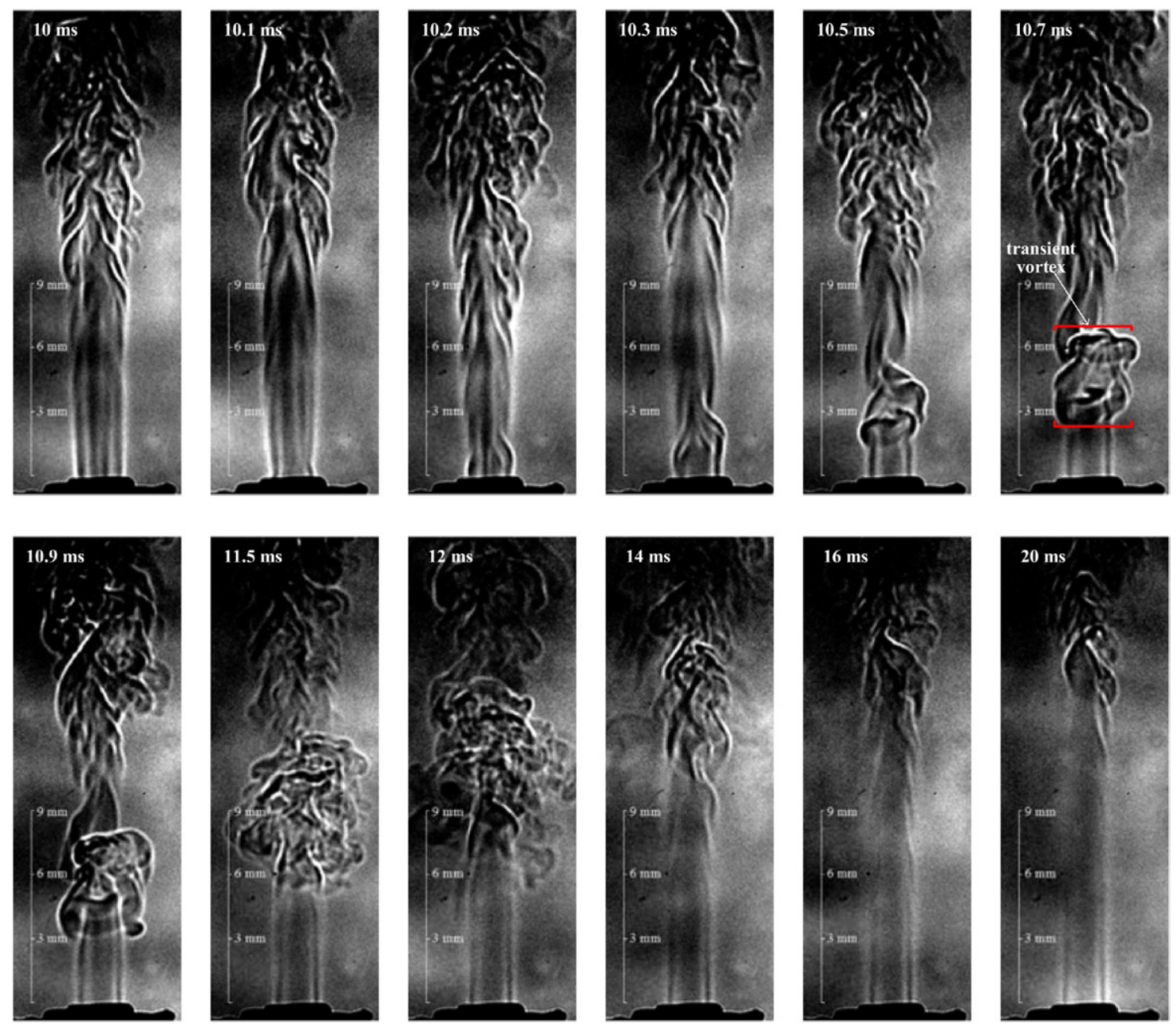

Figure 9. $50 \mathrm{~Hz}$ modulation, time resolved shadowgraphy after the plasma is switched off at $10 \mathrm{~ms}$. On the image of $10.7 \mathrm{~ms}$, the transient vortex structure is marked.

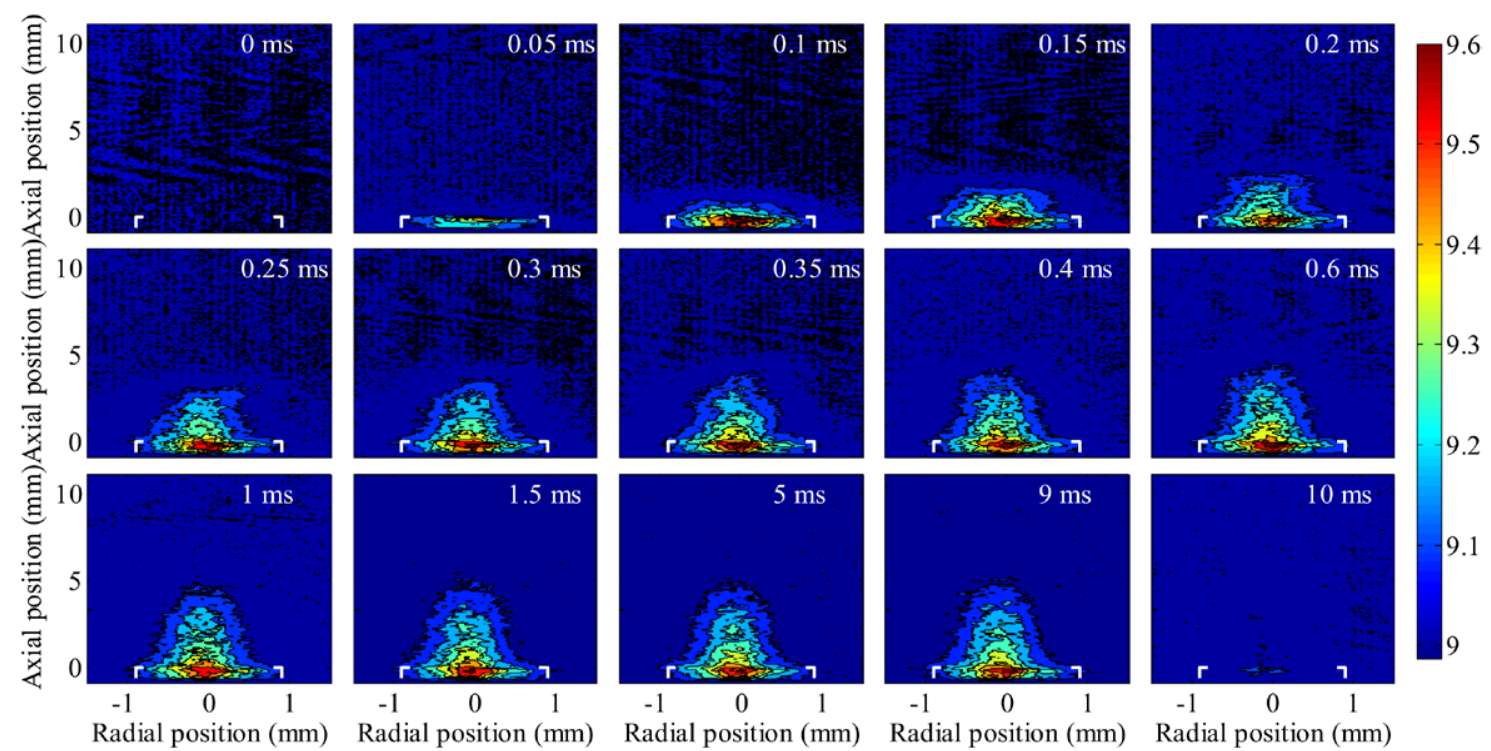

Figure 10. Time and spatially resolved plasma emission profiles. The operating conditions are identical to the ones in figure 8 . The white corners indicate the exit of the quartz. The intensity is shown in a logarithmic scale in arbitrary units. 


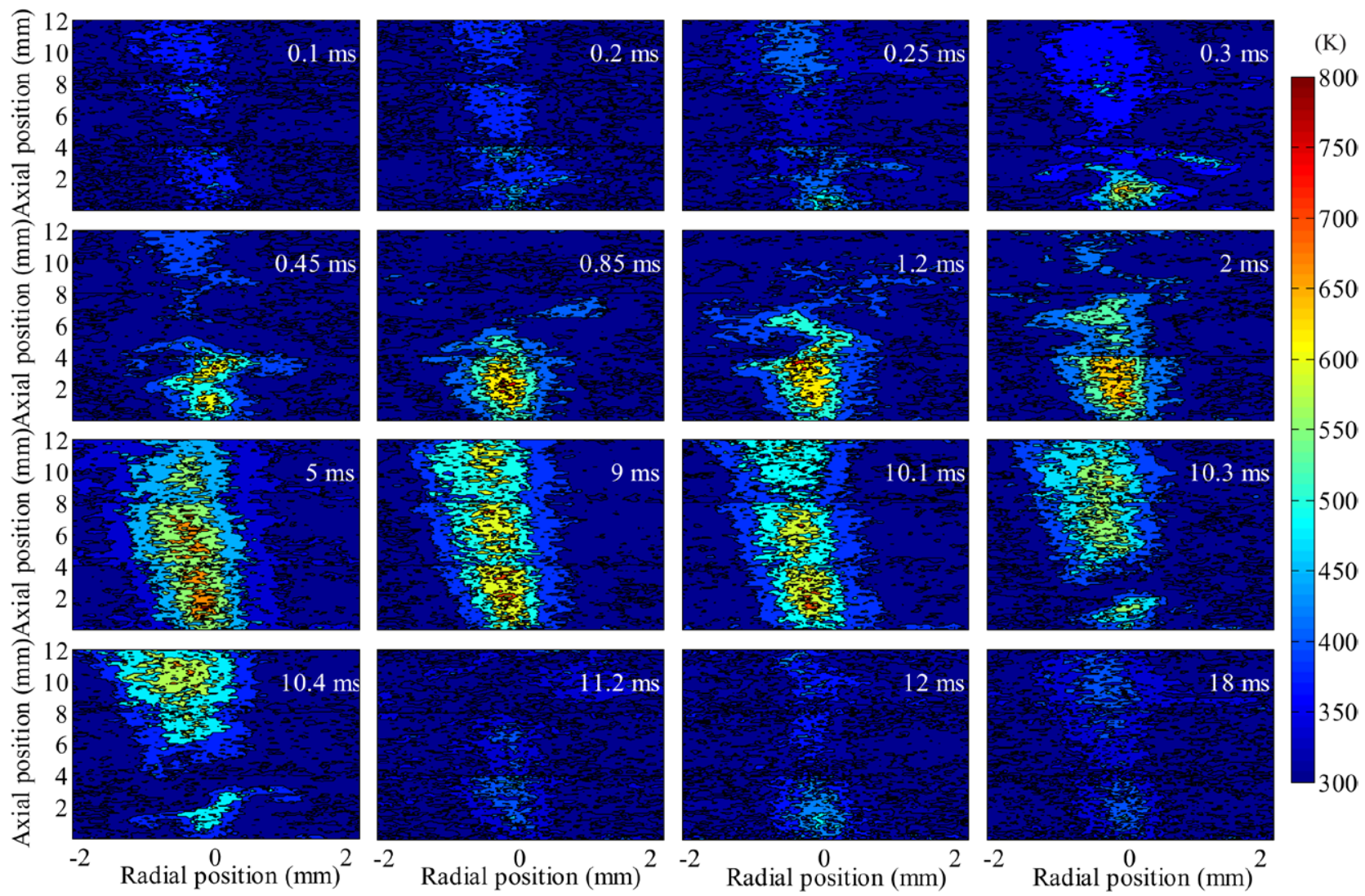

Figure 11. Time and spatially resolved gas temperature profiles. The operating conditions are the same as the ones in figure 8 .

compared to the $50 \mathrm{~Hz}$ case might be responsible for the faster development of the discharge.

The corresponding spatially and time resolved gas temperature profiles are shown in figure 11. An irregular high gas temperature zone is formed after the plasma is ignited between 0.1 and $0.3 \mathrm{~ms}$. This high gas temperature zone extends along the axial direction, as observed in the shadowgraphy measurements. Upstream from this high gas temperature zone, the gas temperature distribution has a profile symmetric around the centerline. Similarly, after the plasma is switched off, a low gas temperature zone is formed as shown on the image at $10.3 \mathrm{~ms}$ and $10.4 \mathrm{~ms}$. This low gas temperature also evolves axially and radially and propagates upwards.

\subsection{Flow dynamics as a function of average dissipated power}

As shown in figure 12, the effective potential core length when the plasma is on does not change monotonically as function of the dissipated power. This length has a minimum at $\sim 6 \mathrm{~W}$, while for the plasma-off phase, the onset position of the large scale vortex is constant at $9 \mathrm{~mm}$ from the quartz tube exit and the effective potential core length is roughly $13 \mathrm{~mm}$.

Images of the visible plasma jet in figure 13 illustrate that the length of the plasma jet increases with increasing power, from $\sim 4 \mathrm{~mm}$ when the average dissipated power is $1.7 \mathrm{~W}$ to $\sim 9 \mathrm{~mm}$ when the dissipated power is $8.1 \mathrm{~W}$.

\section{Discussions}

\subsection{The effective potential core flow length}

4.1.1. Effect of Reynolds and Richardson numbers. In a gas jet with a circular cross-section such as studied in this work, the initial conditions in the quartz tube determine the flow dynamics in the near field region and the intermediate region as defined in $[6,11,12]$. The Reynolds number (equation (1)) is considered as one of determining factors of these initial conditions together with gas velocity at the exit of the quartz tube. They will both be affected by the gas heating and plasma constituents.

$$
\operatorname{Re}=\frac{\rho v D}{\mu}
$$

where $\rho$ is the gas density; $v$ is the gas velocity; D is the characteristic length, which equates the inner quartz tube diameter and $\mu$ is the dynamic viscosity [45].

Combining the data presented in table 2 and figure 3, Vortex structures appear closer to the exit of the quartz tube when the Reynolds number increases. It should also be noted in table 2 that even when the plasma is off in figures $3(a)-(f)$, at the exit of the quartz tube the gas is not at room temperature.

At a given gas flow, the temperature at the exit of the quartz tube increases when the plasma is on, increasing the gas velocity at the quartz tube exit. The continuity equation postulates the following: 

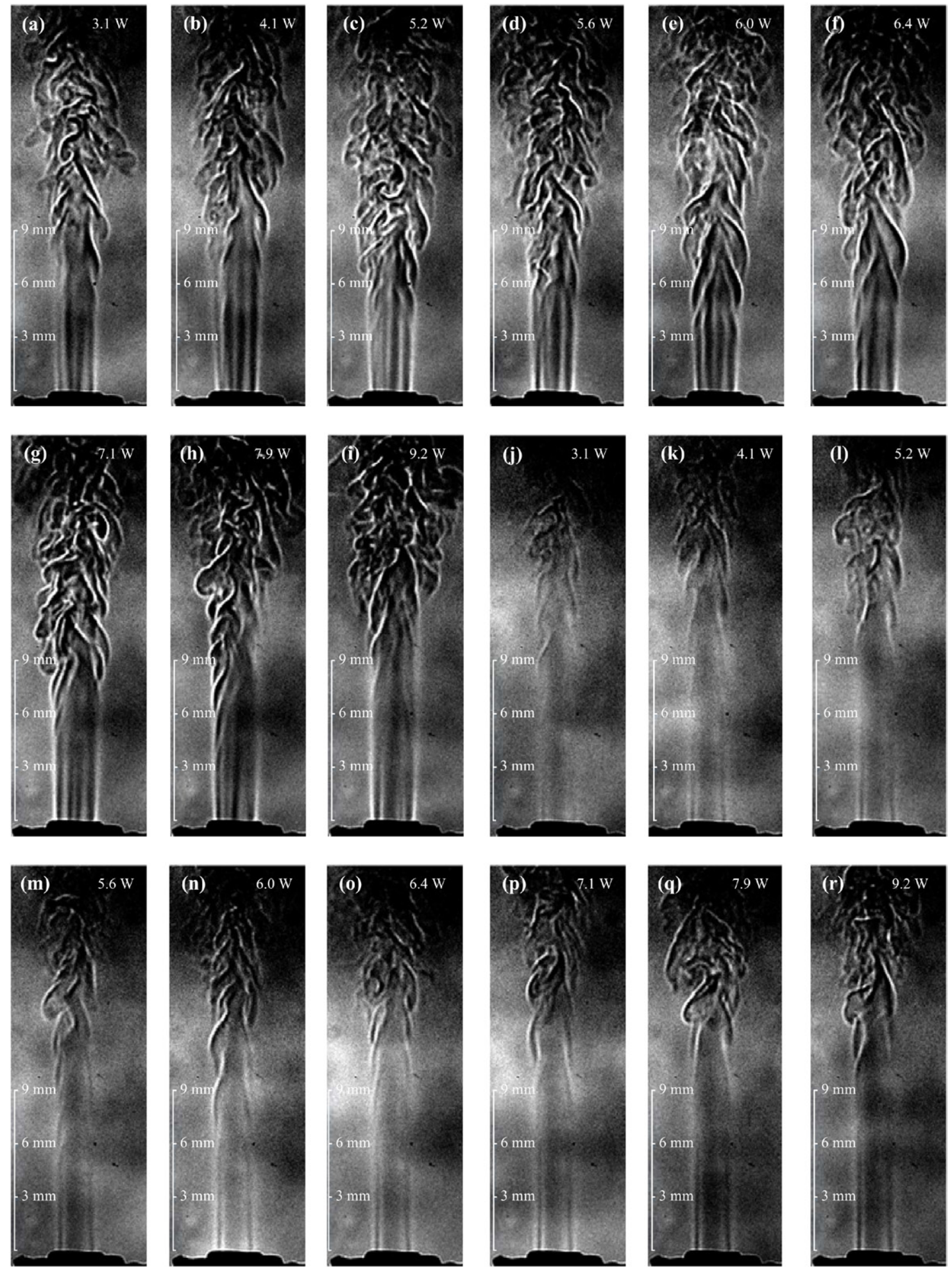

Figure 12. Flow patterns as a function of average dissipated power. Images $(a)-(i)$ are obtained during the plasma-on phase at $19 \mathrm{~ms}$, $(j)-(r)$ during the plasma-off phase at $9 \mathrm{~ms}$. The feed gas is argon mixed with $2 \%$ oxygen. The jet is RF-powered using $50 \mathrm{~Hz}$ modulation with $50 \%$ duty cycle. The average dissipated power is indicated in the images. The gas flow rate is $2 \mathrm{slm}$.

$$
\rho_{\text {plasma on }} v_{\text {plasma on }} D=\rho_{\text {plasma off }} v_{\text {plasma off }} D
$$

Consequently, the $\rho v$ in equation (1) remains constant.

According to equation (1), the Reynolds number decreases when the plasma is on because of the increase in $\mu$. Still, for a given gas flow in figure 3 , the first vortex structure at the edge of the effluent appears closer to the exit of the quartz tube in the plasma-on phase than in the plasma-off phase, regardless to the lower value of the Reynolds number. Consequently, the change in the value of the Reynolds number does not correlate with the length of the effective potential core flow and the appearance of the first vortex structure. 

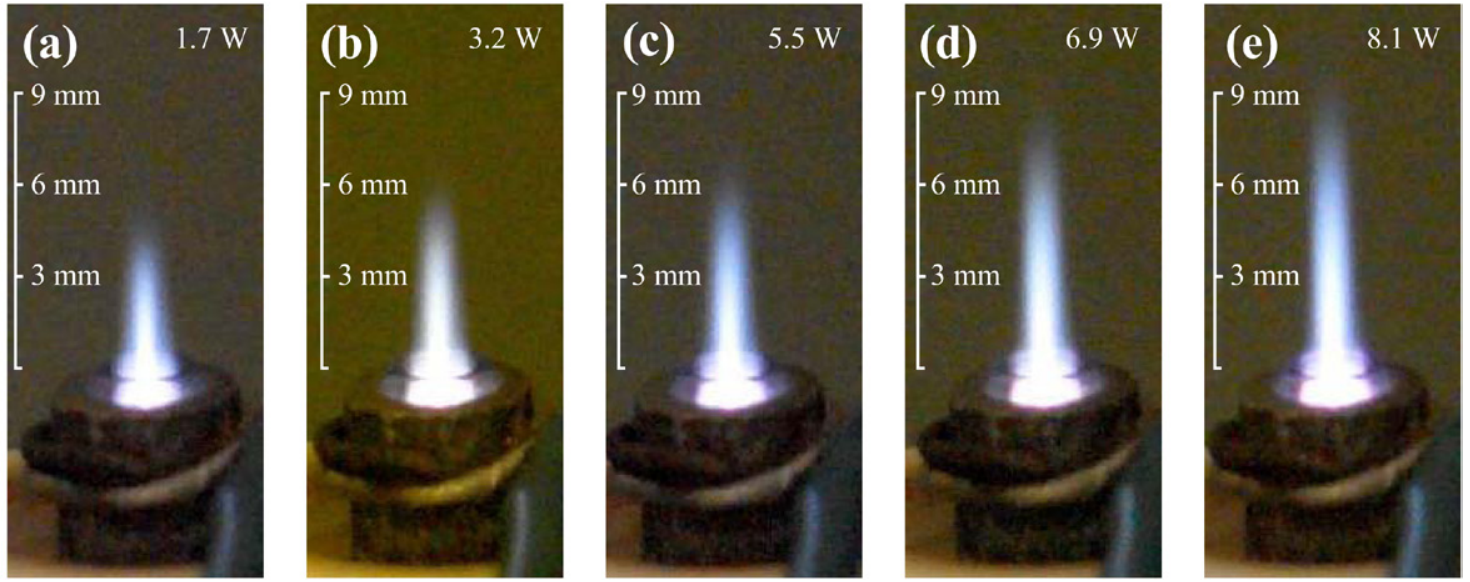

Figure 13. Photographs of plasma effluent at different powers. The feed gas is argon mixed with $2 \%$ oxygen. The flow rate is 2 slm. The power is marked on the image.

Table 2. The Reynolds numbers under different flow rate in figure 3.

\begin{tabular}{|c|c|c|c|c|c|c|c|}
\hline \multicolumn{2}{|l|}{ Ar flow rate (slm) } & 1.5 & 2.0 & 2.5 & 3.0 & 3.5 & 4.0 \\
\hline \multicolumn{2}{|c|}{ Ar flow velocity at $300 \mathrm{~K}\left(\mathrm{~m} \mathrm{~s}^{-1}\right)$} & 8.0 & 10.6 & 13.3 & 15.9 & 18.6 & 21.2 \\
\hline \multirow[t]{2}{*}{ Gas temperature $(\mathrm{K})^{\mathrm{a}}$} & plasma on & 870 & 745 & 735 & 640 & 635 & 605 \\
\hline & plasma off & 450 & 450 & 450 & 450 & 450 & 450 \\
\hline \multirow[t]{2}{*}{ Reynolds number ${ }^{\mathrm{b}}$} & plasma on & 518 & 764 & 955 & 1273 & 1485 & 1797 \\
\hline & plasma off & 764 & 1018 & 1273 & 1528 & 1782 & 2037 \\
\hline
\end{tabular}

Note that the viscosity of the argon plasma might differ from the viscosity of the pure gas flow, however, to the authors' knowledge, there is no such data for non-equilibrium plasma available in literature, so the viscosity is chosen from the property of pure gas flow without plasma.

The Richardson number (equation (3)) expresses the ratio of potential to kinetic energy and as such reflects the influence of buoyancy on the flow. If $\mathrm{Ri}>>1$, there is insufficient kinetic energy to homogenize the fluids and buoyancy is dominant in the flow, however if $\mathrm{Ri}<<1$ buoyancy has no strong effect on the flow.

$$
\mathrm{Ri}=\frac{D g\left(\rho_{\infty}-\rho_{\mathrm{gas}}\right)}{v^{2} \rho_{\mathrm{gas}}}
$$

where $v$ is the gas velocity; $D$ is the characteristic length; $g$ is the gravitational acceleration; $\rho_{\infty}$ and $\rho_{\text {gas }}$ are the gas density of the surrounding and the core zone, respectively.

For the region from the exit of the quartz tube to the onset of first vortex structure the gas velocity and the characteristic length can be approximated as equal to the initial conditions at the exit of the quartz tube [5]. The gas density at the core zone depends on the gas temperature and the Richardson number is approximately $\mathrm{Ri} \sim 10^{-4}$; consequently the buoyancy effect due to the density differences should not be important throughout the investigated region. Indeed the density ratio Ar-air is 1.54 at room temperature and reaches 0.5 for the heated jet. This is still significantly larger than for the He jet at room temperature.
Table 3. Gas flow velocity for the condition of 2 slm argon $+2 \%$ $\mathrm{O}_{2}$ as shown in figures $3(b)$ and $(h)$ at the position of the exit of the quartz tube.

\begin{tabular}{lll}
\hline & Plasma on & Plasma off \\
\hline Gas temperature $(\mathrm{K})$ & 745 & 450 \\
Gas velocity $\left(\mathrm{m} \mathrm{s}^{-1}\right)$ & 26.3 & 15.9 \\
\hline
\end{tabular}

4.1.2. Effect of flow velocity. As shown in figure 3, the increase in gas flow velocity at the quartz tube exit causes the decrease in the effective potential core flow length. The increase in flow velocity can come from experiment control (increasing the gas flow) or by switching on the plasma and increasing gas temperature, as shown in table 3.

The reason for the appearance of vortex structures at the edge of the effluent stems from the velocity gradient between the effluent of the jet and the surrounding air. Due to the velocity difference a perturbation develops in a thin layer at the edge of the effluent where vortex structures start forming, as reported in [20]. For a larger velocity difference, the perturbation develops earlier in the jet and the vortex structures appear closer to the exit of the quartz tube and the effective potential core length reduces.

Velocity gradients also lead to Kelvin-Helmholtz instabilities [12, 17, 23]. Particularly in reports of simulations performed for a DC arc plasma jet this mechanism is highlighted [19]. However, further work is needed to show whether Kelvin-Helmholtz instabilities are triggered by the plasma and involved in the initial formation of the observed large vortex structures under the present experimental conditions. 


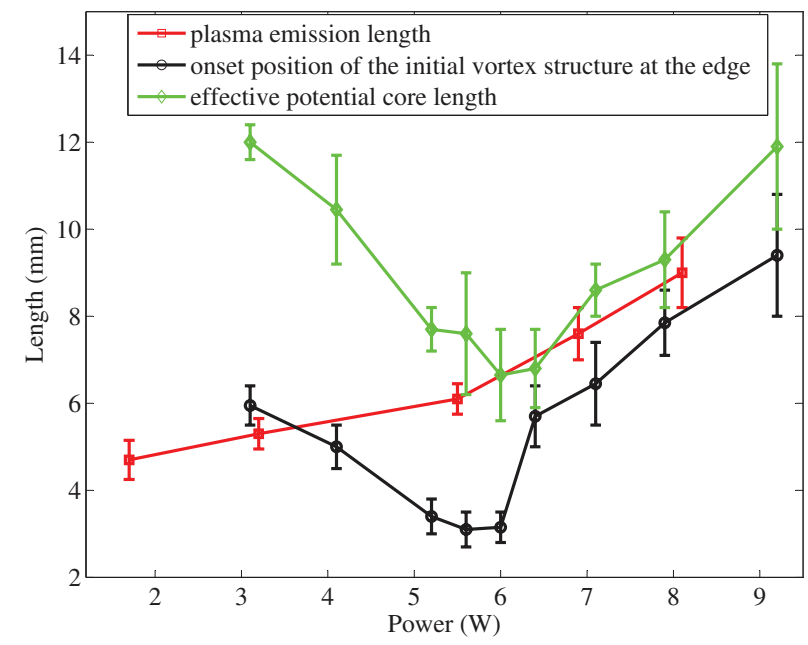

(a)

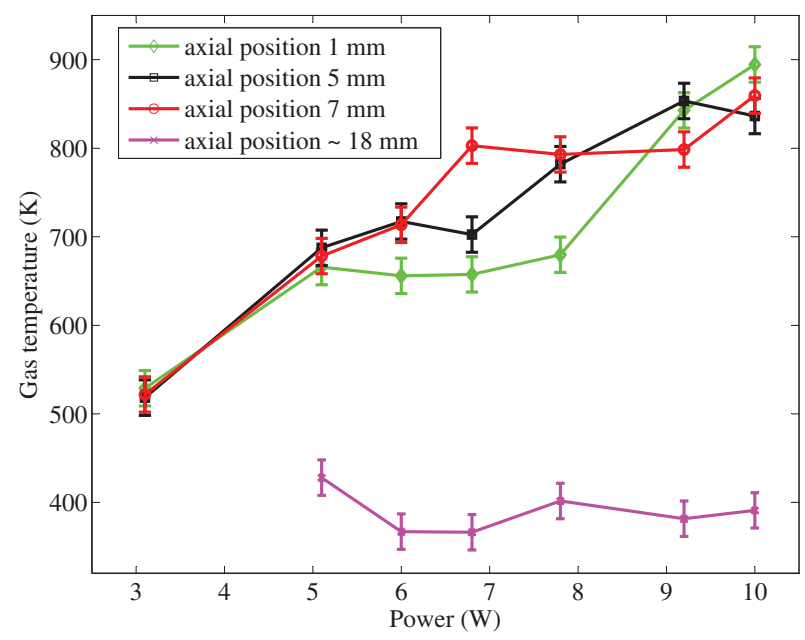

(b)

Figure 14. The effective potential core length and the onset position of vortex structures at the edge of the effluent and the visible plasma emission $(a)$ and the gas temperature distribution $(b)$ at variable powers. The gas temperature is obtained on the axis of symmetry. The error bar of effective potential core flow length is estimated on the stream line formed along the flow.

4.1.3. The effect of ion momentum transfer. As mentioned previously, there is debate whether the momentum transfer from ions or ion wind to neutrals may accelerate the velocity of the gas flow in APPJs [27]. The momentum transfer from ions to neutrals is represented by the electrohydrodynamics (EHD) force and widely investigated in plasma actuators to manipulate the flow in the near wall boundary layer by increasing the velocity in the boundary [46-49]. A necessary condition for this effect to be important is the occurrence of zones with space charge separation. In the jet itself this can be achieved in the ionization fronts. If the effect of the ion drag would be important compared to e.g. thermal effects, one should observe some obvious flow pattern distortion when the plasma is switched off and/or on, which is not the case at $20 \mathrm{kHz}$ modulation as shown in figure 5.

While in guided streamers (or plasma bullets) the streamer head propagation induces a charge separation this is less likely the case at $13.5 \mathrm{MHz}$ as the electron density remains constant during one RF cycle [22]. Nonetheless it is found that the visual emission of the plasma is growing on a time scale of $0.4 \mathrm{~ms}$ (for the $50 \mathrm{~Hz}$ modulation case) and $3 \mathrm{us}$ (for the $20 \mathrm{kHz}$ modulation case) (see section 3.3). Charge separation will be present at the edge of this growing ionization front. We use the approach of Boeuf et al to estimate an order of magnitude of the ion momentum transfer possibly generated by this process [50]. The intensity of the electric field $\sim 100 \mathrm{~V} \mathrm{~cm}^{-1}$ as deduced from a maximum expected $T_{e}$ of $3 \mathrm{eV}$ in an $\mathrm{Ar}$ plasma $[22,51]$. The propagation velocity of the growing ionization front over several RF cycles has been found by van Gessel et al in a similar jet to be $10-100 \mathrm{~km} \mathrm{~s}^{-1}$ when only considering the $\mathrm{N}_{2}(C)$ emission [52]. From the non-spectral resolved images in figures 6 and 10, a maximum velocity of the order of $1 \mathrm{~km} \mathrm{~s}^{-1}$ can be deduced in the $20 \mathrm{kHz}$ case while $10 \mathrm{~m} \mathrm{~s}^{-1}$ in the $50 \mathrm{~Hz}$ case. Considering that the gas temperature is of the order of $900 \mathrm{~K}$, the increased velocity due to the EHD force $\left(\Delta v \approx \varepsilon_{0} E^{2} /\left(\rho_{\text {gas }} v_{\text {bullet }}\right)\right)$ (for the lowest velocity) is most likely on the order of $10^{-4} \mathrm{~m} \mathrm{~s}^{-1}$, at least four orders of magnitude smaller than the flow velocity. This confirms the experimental conclusion that the effect of ion wind on the gas flow velocity close to the quartz tube exit will be negligible.

\subsubsection{The effect of average dissipated power. Figure 14(a)} shows that the effective potential core flow length is not a linear function of the dissipated power. Also, at $\sim 6 \mathrm{~W}$ the visual plasma length equals the potential core length and for higher powers both the visual plasma length and potential core length increase.

Increasing gas heating would lead to increased velocities and an earlier perturbation development in the jet as discussed above. However, the change in Ar viscosity with temperature could be responsible for the delayed onset of the vortex structures at the edge of the effluent at higher powers. This effect might become more pronounced in the transition region with the increase in plasma length and increase gas temperature in the far effluent in figure $14(b)$. Besides the gas temperature dependence of the viscosity, the produced plasma might also affect viscosity [53, 54].

Although experiments at average powers of $6.5 \mathrm{~W}$ at $50 \mathrm{~Hz}$ and $3.5 \mathrm{~W}$ at $20 \mathrm{kHz}$ modulation have shown that the effect of ionic species in the plasma has a negligible effect on the flow, at higher powers significant charge separation can be present at the visible plasma tip in the transition region. Note that also a relatively large amount of ionic species has been measured by mass spectrometry in the near afterglow for this APPJ [55]. The situation close to the visible jet tip might be very similar to the drift zone in a DC corona discharge in which typical flow velocities induced by ion drag of the order of $1 \mathrm{~m} \mathrm{~s}^{-1}$ are found [56]. Even for lower velocity values as estimated above, the effect of EHD force can not be a priori neglected due to the strongly reduced axial jet velocity in the transition regime. Further research, especially the velocity field measurement, is needed to give a definitive conclusion on the nature of the stabilizing effect on the effluent at high powers. 


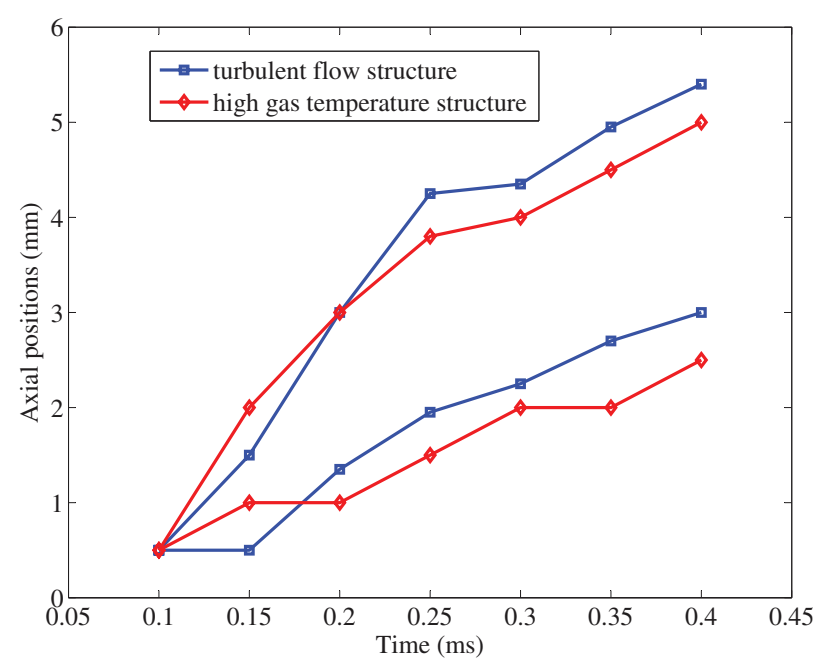

(a)

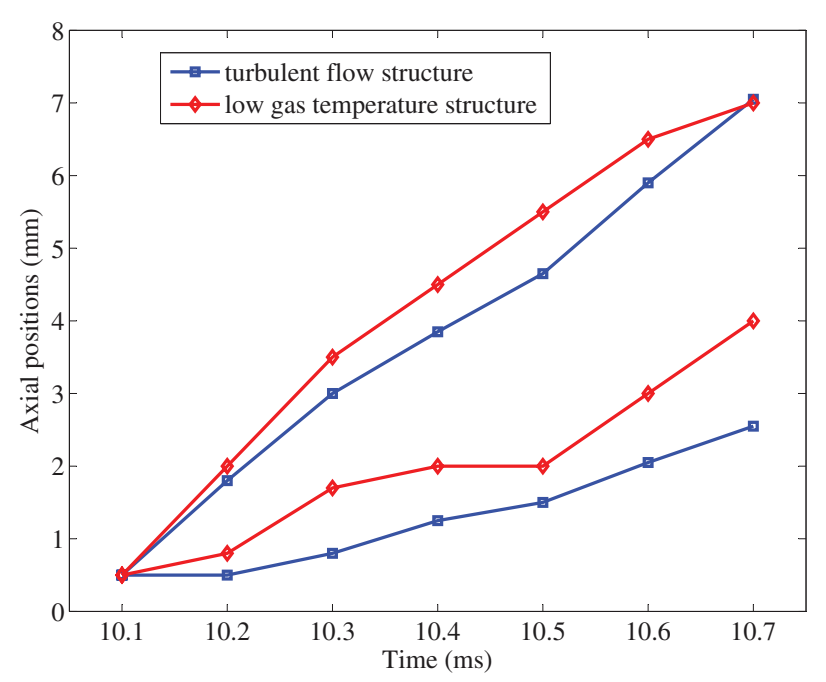

(b)

Figure 15. Upper and lower boundary of the transient vortex structure and the gas temperature structure on the axis of symmetry when the plasma is $(a)$ on $(b)$ off. The zero position is the exit of the quartz tube. $0 \mathrm{~ms}$ and $10 \mathrm{~ms}$ corresponds to the time when the plasma is switched on and off, respectively. The upper and lower markers indicate the axial size of structures. Examples are shown in figures 8 and 9.

\subsection{The origin of the large-scale transient vortex structure}

It is shown in figures 8 and 9 that there is a transient vortex structure formed when the plasma is switched on and off. Compared to the gas temperature distribution, a high gas temperature zone is formed after the plasma is ignited between $0.1-0.3 \mathrm{~ms}$ in figure 11. This high gas temperature zone extends along the axial direction. Its growth velocity is highly correlated with the propagation velocity of the transient vortex structure in the flow as shown in figure $15(a)$ in which both the position of the high gas temperature zone and the transient vortex structure are plotted. When the plasma is switched off a lower gas temperature zone is formed as can be seen in figure 11 at $t=10.3 \mathrm{~mm}$. The growth of the lower temperature zone is also highly correlated to the propagation speed of the transient vortex structure in the flow as is shown in figure $15(b)$.

Based on these correlations we can conclude that the reason behind this phenomenon relates to the difference in velocities of the gas flow originating from the quartz tube when the plasma is on and off. Shortly after the plasma is switched on, the less dense and faster moving flow from the tube interacts with the slower moving flow downstream, forming a vortex in the whole cross-section of the effluent. Similarly when the plasma is switched off, the onset of denser but slower flow from the quartz tube triggers a perturbation in the flow and causes a similar large-scale vortex that travels downstream.

\section{Conclusions}

It is shown for the APPJ studied in this work that the reduction of the effective potential core flow in the plasma effluent is due to gas heating. Gas heating leads to increased gas flow velocities in the early effluent and the induced larger velocity difference triggers the onset of the vortex structures at the jet effluent. The changes in the effective potential core flow length are not found not to be correlated with a change in the Reynolds number.

In addition, it is shown that the velocity change due to gas temperature changes induced by plasma modulation lead to the occurrence of large-scale transient vortex structure of which the propagation velocity strongly correlates with the change in gas temperature distribution.

In the case of higher plasma powers, the plasma is able to stabilize the flow and extend the effective potential core flow length. Two possible explanations are given: (1) stabilizing effects due to an increase in viscosity with increasing gas temperature and (2) charge separation at the edge of the plasma plume leading to ionic momentum transfer.

\section{Acknowledgments}

The authors sincerely thank H Schouten, A Schrader and E Ridderhof for their technical assistance with experiments. SZ and AS would also like to thank Prof A Hirschberg for the discussion on the flow dynamics of the APPJ P B acknowledges funding from Stichting Technische Wetenschappen (the Netherlands), US Department of Energy Office of Fusion Science through the Plasma Science Center and the University of Minnesota.

The authors also thank the referees for their valuable comments.

\section{References}

[1] Kong M G, Kroesen G, Morfill G, Nosenko T, Shimizu T, van Dijk J and Zimmermann J L 2009 New J. Phys. 11 115012

[2] Laroussi M 2009 IEEE Trans. Plasma Sci. 37 714-25

[3] Reuter R, Rügner K, Ellerweg D, de los Arcos T, von Keudell A and Benedikt J 2012 Plasma Process. Polym. 9 1116-24 
[4] Gauntner J W, Livingood J N and Hrycak P 1970 Survey of Literature on Flow Characteristics of a Single Turbulent Jet Impinging on a Flat Plate (Washington, DC: National Aeronautics and Space Administration)

[5] Labus T L and Symons E P 1972 Experimental Investigation of an Axisymmetric Free Jet with an Initially Uniform Velocity Profile (Washington, DC: National Aeronautics and Space Administration)

[6] Grandchamp X and Van Hirtum A 2013 Flow Turbul. Combust. 90 95-119

[7] Abdel-Rahman A 2010 WSEAS Trans. Fluid Mech. 5 257-75

[8] Russ S and Strykowski P 1993 Phys. Fluids A: Fluid Dyn. (1989-1993) 5 3216-25

[9] Pitts W M 1991 Exp. Fluids 11 125-34

[10] Kyle D and Sreenivasan K 1993 J. Fluid Mech. 249 619-64

[11] Kozlov V V, Grek G R, Dovgal A V and Litvinenko Y A 2013 J. Flow Control Meas. Vis. 194

[12] Litvinenko Y A, Grek G, Kozlov G, Sorokin A and Litvinenko M 2012 Development of a free round jet at different conditions at the nozzle exit under an acoustic action Progress in Flight Physics vol 3 (Les Ulis: EDP Sciences) pp 429-8

[13] Yildirim B and Agrawal A 2005 Exp. Fluids 38 161-73

[14] Pasumarthi K S and Agrawal A K 2005 Exp. Fluids 38 541-4

[15] Rehab H, Villermaux E and Hopfinger E 1997 J. Fluid Mech. $345357-81$

[16] Takahashi F, Mizomoto M and Ikai S 1982 Combust. Flame 48 85-95

[17] Takeno T 1994 Transition and structure of jet diffusion flames Symposium (International) on Combustion vol 25 (Amsterdam: Elsevier) pp 1061-73

[18] Russ S, Strykowski P and Pfender E 1994 Exp. Fluids 16 297-307

[19] Trelles J P 2013 J. Phys. D: Appl. Phys. 46255201

[20] Pfender E, Fincke J and Spores R 1991 Plasma Chem. Plasma Process. 11 529-43

[21] Barnes R and Genna J 1981 Spectrochim. Acta B: At. Spectrosc. 36 299-323

[22] van Gessel B, Brandenburg R and Bruggeman P 2013 Appl. Phys. Lett. 103064103

[23] Takamura S, Saito S, Kushida G, Kando M and Ohno N 2010 IEEJ Trans. Fundam. Mater. $130493-500$

[24] Oh J S, Olabanji O T, Hale C, Mariani R, Kontis K and Bradley J W 2011 J. Phys. D: Appl. Phys. 44155206

[25] Bradley J W, Oh J S, Olabanji O T, Hale C, Mariani R and Kontis K 2011 IEEE Trans. Plasma Sci. 39 2312-3

[26] Ghasemi M, Olszewski P, Bradley J and Walsh J 2013 J. Phys. D: Appl. Phys. $\mathbf{4 6} 052001$

[27] Foletto M, Douat C, Fontane J, Joly L, Pitchford L and Puech V 2013 31th Int. Conf. on Phenomena in Ionized Gases (Granada, Spain, 14-19 July 2013)

[28] Robert E, Sarron V, Darny T, Riès D, Dozias S, Fontane J, Joly L and Pouvesle J 2014 Plasma Sources Sci. Technol. 23012003
[29] Sarron V, Robert É, Fontane J, Darny T, Riès D, Dozias S, Joly L and Pouvesle J M 2013 21 st Int. Symp. on Plasma Chemistry (Cairns, Australia, 4-9 August 2013)

[30] Boselli M, Colombo V, Ghedini E, Gherardi M, Laurita R, Liguori A, Sanibondi P and Stancampiano A 2014 Plasma Chem. Plasma Process. 34 853-69

[31] Papadopoulos P, Vafeas P, Svarnas P, Gazeli K, Hatzikonstantinou P, Gkelios A and Clément F 2014 J. Phys. D: Appl. Phys. 47425203

[32] Mericam-Bourdet N, Laroussi M, Begum A and Karakas E 2009 J. Phys. D: Appl. Phys. 42055207

[33] Xu D Y and Chen X 2005 Int. Commun. Heat Mass Transfer 32 939-46

[34] Cheng K and Chen X 2004 Int. J. Heat Mass Transfer 47 5139-48

[35] Woodfield P, Nakabe K and Suzuki K 2000 Japan Soc. Comput. Fluid Dyn. 14 95-101

[36] Samukawa S et al 2012 J. Phys. D: Appl. Phys. 45253001

[37] Sharp K V and Adrian R J 2004 Exp. Fluids 36 741-7

[38] Adrian R and Yao C 1986 Exp. Fluids 5 17-28

[39] Zhang S, van Gaens W, van Gessel B, Hofmann S, van Veldhuizen E, Bogaerts A and Bruggeman P 2013 J. Phys. D: Appl. Phys. 46205202

[40] Zhang S, van Gessel A, van Grootel S and Bruggeman P 2014 Plasma Sources Sci. Technol. 23025012

[41] Hofmann S, van Gessel A F H, Verreycken T and Bruggeman P 2011 Plasma Sources Sci. Technol. 20065010

[42] van Gessel A F H, Carbone E A D, Bruggeman P J and van der Mullen J 2012 Plasma Sources Sci. Technol. 21015003

[43] De Regt J M, De Groote F P J, van der Mullen J A M and Schram D C 1996 Spectrochim. Acta B: At. Spectrosc. 51 1527-34

[44] Sutton J A and Driscoll J F 2004 Opt. lett. 29 2620-2

[45] Bich E, Millat J and Vogel E 1990 J. Phys. Chem. Ref. Data 19 1289-305

[46] Moreau E 2007 J. Phys. D: Appl. Phys. 40605

[47] Moreau E, Benard N, Lan-Sun-Luk J D and Chabriat J P 2013 J. Phys. D: Appl. Phys. 46475204

[48] Boeuf J and Pitchford L 2005 J. Appl. Phys 97103307

[49] Leger L, Moreau E and Touchard G G 2002 IEEE Trans. Indust. Appl. 38 1478-85

[50] Boeuf J, Lagmich Y, Unfer T, Callegari T and Pitchford L 2007 J. Phys. D: Appl. Phys. 40652

[51] Raizer Y P, Kisin V I and Allen J E 1991 Gas Discharge Physics vol 1 (Berlin: Springer)

[52] van Gessel A, Alards K and Bruggeman P 2013 J. Phys. D: Appl. Phys. 46265202

[53] Sosa R, Arnaud E, Memin E and Artana G 2009 IEEE Trans. Dielectr. Electr. Insul. 16 305-11

[54] Fortov V, Petrov O, Vaulina O and Timirkhanov R 2012 Phys. Rev. Lett. 109055002

[55] van Gils C, Hofmann S, Boekema B, Brandenburg R and Bruggeman P 2013 J. Phys. D: Appl. Phys. 46175203

[56] Kawamoto H, Yasuda H and Umezu S 2006 J. Electrostat. 64 400-7 